\title{
Circularly Polarized Transparent Microstrip Patch Reflectarray Integrated with Solar Cell for Satellite Applications
}

\author{
S. H. Zainud-Deen, ${ }^{1}$ N. A. El-Shalaby, ${ }^{2}$ S. M. Gaber, ${ }^{3}$ and H. A. Malhat ${ }^{1}$ \\ ${ }^{1}$ Faculty of Electronic Engineering, Menoufia University, Monufia, Egypt \\ ${ }^{2}$ Faculty of Engineering, Kafrelsheikh University, Kafr El-Sheikh, Egypt \\ ${ }^{3}$ Faculty of Engineering, Egyptian Russian University, Cairo, Egypt
}

Correspondence should be addressed to N. A. El-Shalaby; noha1511ahm@yahoo.com

Received 6 March 2016; Revised 16 July 2016; Accepted 23 August 2016

Academic Editor: Safieddin Safavi-Naeini

Copyright (C) 2016 S. H. Zainud-Deen et al. This is an open access article distributed under the Creative Commons Attribution License, which permits unrestricted use, distribution, and reproduction in any medium, provided the original work is properly cited.

Circularly polarized (CP) transparent microstrip reflectarray antenna is integrated with solar cell for small satellite applications at $10 \mathrm{GHz}$. The reflectarray unit cell consists of a perfect electric conductor (PEC) square patch printed on an optically transparent substrate with the PEC ground plane. A comparison between using transparent conducting polymers and using the PEC in unit-cell construction has been introduced. The waveguide simulator is used to calculate the required compensation phase of each unit cell in the reflectarray. The radiation characteristics of $13 \times 13 \mathrm{CP}$ transparent reflectarray antenna are investigated. A circularly polarized horn antenna is used to feed the reflectarray. The solar cell is incorporated with the transparent reflectarray on the same area. The solar-cell integration with the reflectarray reduces the maximum gain by about $0.5 \mathrm{~dB}$ due to the increase in the magnitude of the reflection coefficient. The results are calculated using the finite integral technique (FIT).

\section{Introduction}

Recently, high-gain reconfigurable microwave antennas have emerged in many applications as radar and satellite communications [1]. The reflectarray has several advantages such as low profile, light weight, less cost, and the fact that it can work at millimeter-wave frequencies without suffering from insertion losses associated with the phased array. The disadvantage of the reflectarray is narrow bandwidth, which generally cannot exceed much beyond $10 \%$, depending on its element design and its aperture size, such as the microstrip patch element [2-4]. Various techniques are employed to enhance the reflectarray bandwidth by using thick substrate for the patch, stacking multiple patches $[5,6]$, and aperture coupled microstrip patches [7]. A reflectarray antenna combines some of the best characteristics of the parabolic reflector antennas and phased array antennas [8]. The reflectarray consists of a planar surface of many units cells with perfect electrical ground plane (PEC) illuminated by a primary feeding source, usually horn antenna [9]. The feed signal is reflected from the reflectarray structure, transforming the spherical feed wavefront to a plane wave. Microstrip reflectarrays are very attractive aperture antennas because of their planar structure and a simple feed system $[10,11]$.

Recently, transparent conducting polymers have been used instead of copper in microstrip patch antenna fabrications. Transparent conducting films (TCFs) are suitable to be implemented with clear substrates for emerging applications such as security, aesthetics [12, 13], and vehicles [14] or can be integrated with solar cells to save surface area of small satellites [15]. TCFs allow the transmission of electric currents and keep back the optical transparency [16]. There are three types of TCFs used by researchers for antenna developments, namely, indium tin oxide (ITO), fluorine-doped tin oxide (FTO), and silver coated polyester films (AgHT) [17].

By employing the integration technologies, the antennas are used for data communication and the solar cells are used for energy harvesting, saving the available surface area of emerging applications [18-24]. Integrating both the antennas and solar cells yields significant area savings and 


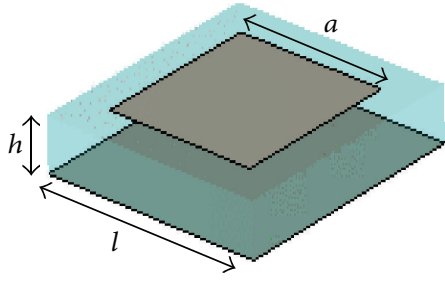

(a) $3 \mathrm{D}$ view

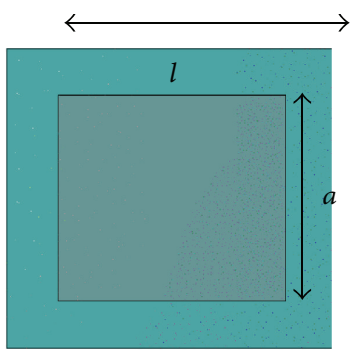

(b) Top view

Figure 1: The detailed construction of the PEC/optically transparent microstrip patch unit cell.

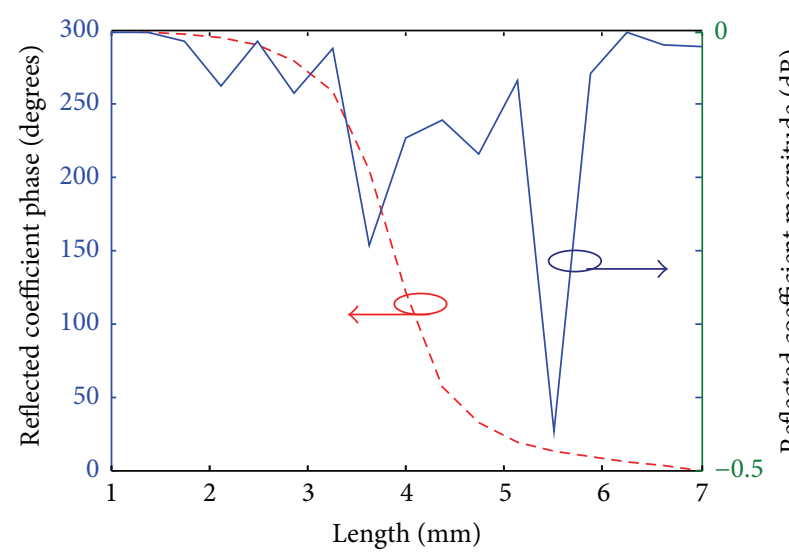

(a) The PEC unit cell

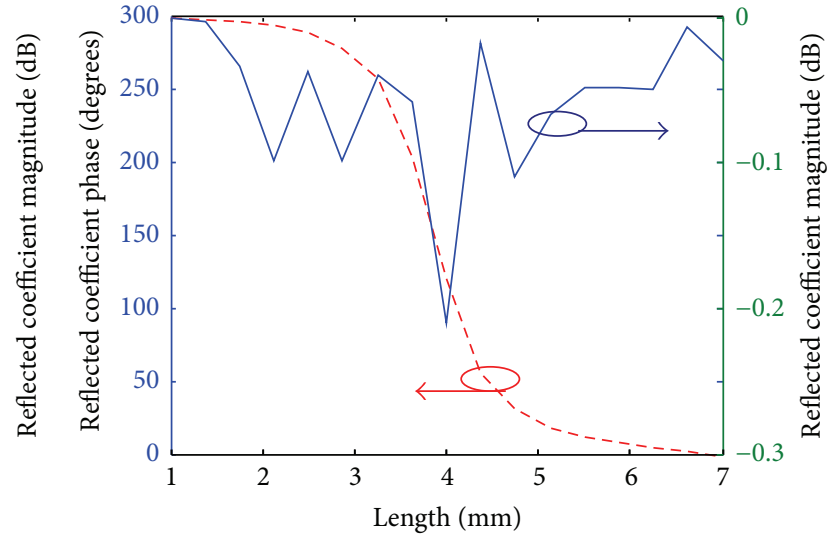

(b) The optically transparent unit cell

FIGURE 2: The reflection coefficient magnitude and phase variation versus the patch arm length at $10 \mathrm{GHz}$ for the PEC/TCFs patch unit cell.

improves the economic viability of the renewable energy. In open literature, there are three types of antenna integration techniques that have been reported. The first type is to place a patch microstrip antenna under solar cells [10]. The second type is to use slot patch antennas and deposit solar cells directly on top of them $[11,25]$. The third type is to integrate antennas that are transparent to light immediately on top of commercial solar cells [8].

In this paper, a design of $13 \times 13$ circularly polarized transparent microstrip patch reflectarray antenna is investigated. The reflectarray antenna consists of 169 unit cells; each is a square patch printed on an optically transparent dielectric substrate and a PEC ground plane. A comparison between the radiation characteristics of the reflectarray consists of PEC microstrip patches and TCFs patch has been investigated. An integration of the solar cell with the microstrip reflectarray antenna for small satellite applications has been presented. The finite integral technique (FIT) [26] is employed to investigate the radiation characteristics of the optically transparent reflectarray integrated with the solar cell.

\section{Numerical Results}

2.1. Unit-Cell Design. The detailed construction of the reflectarray unit cell is shown in Figure 1. The unit cell is a PEC square patch with arm length, $a$, printed on a square optically transparent dielectric substrate with dielectric constant $\varepsilon_{r}=$ 2.33, and dimensions $14.6 \times 14.6 \times 1.95 \mathrm{~mm}^{3}$. A square PEC ground plane is printed on the back side of the dielectric substrate. The unit cell is designed to operate at $10 \mathrm{GHz}$. To calculate the required reflection coefficient compensation phase shift, the unit cell is placed in a waveguide simulator [18]. The waveguide simulator is used to simulate an infinite array approximation by applying perfect electric and magnetic boundary conditions to the sides of the waveguide (i.e., image theory). A linearly polarized plane wave is used to normally excite the unit cell. The infinite array approach has several limitations. In the first approach, all elements of the reflectarray are identical, which is not the case in the real reflectarray. Secondly, the reflectarray itself is not infinite in extent. Figure 2(a) shows the variation of the reflection coefficient magnitude and phase versus the PEC patch arm's length, $a$, at $10 \mathrm{GHz}$. The reflection coefficient magnitude achieves nearly $0 \mathrm{~dB}$ due to the high conductivity of the PEC patch and ground plane. The phase of the reflection coefficient varies from 0 to $300^{\circ}$ for patch arm length varying from $1 \mathrm{~mm}$ to $7 \mathrm{~mm}$. In order to improve the optical transparency of the reflectarray unit cell, an optically transparent conducting polymer TCF with $\sigma=5 \times 10^{5} \mathrm{~S} / \mathrm{m}$ is used instead of the PEC patch and the ground plane. The variation of the reflection coefficient magnitude and phase with the patch arm length at $10 \mathrm{GHz}$ is shown in Figure 2(b). 


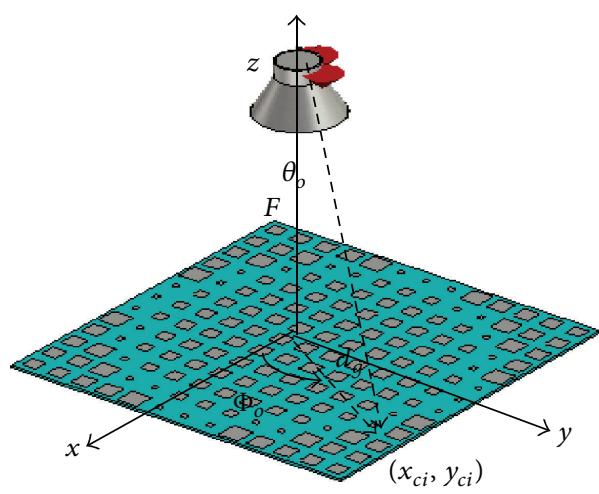

(a) $3 \mathrm{D}$ view

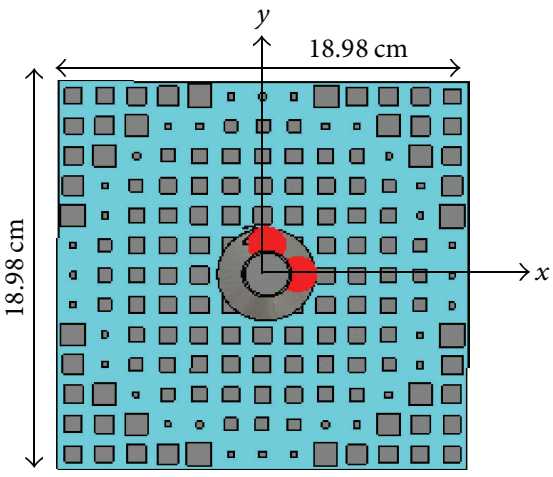

(b) Top view

Figure 3: The detailed construction of the PEC/optically transparent microstrip patch reflectarray.

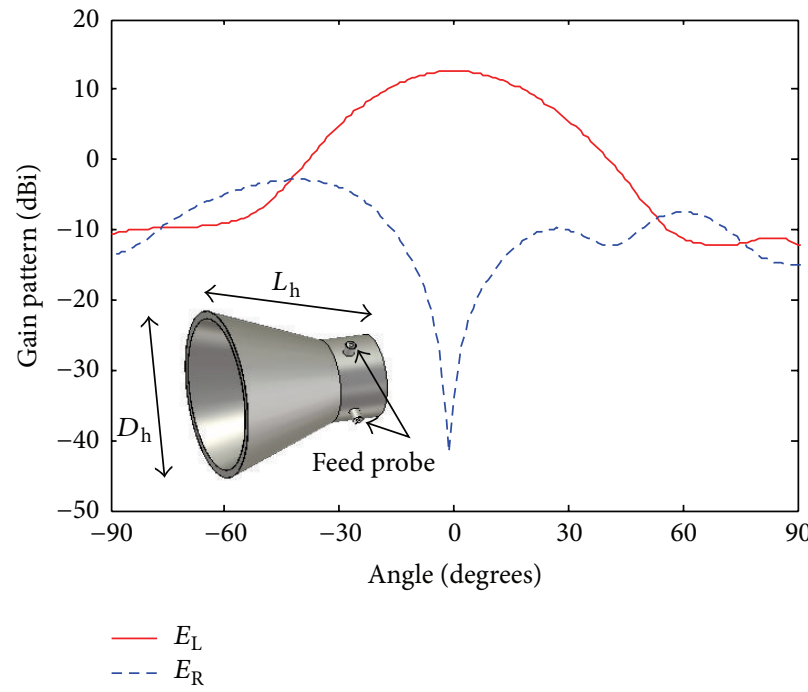

(a) E-plane

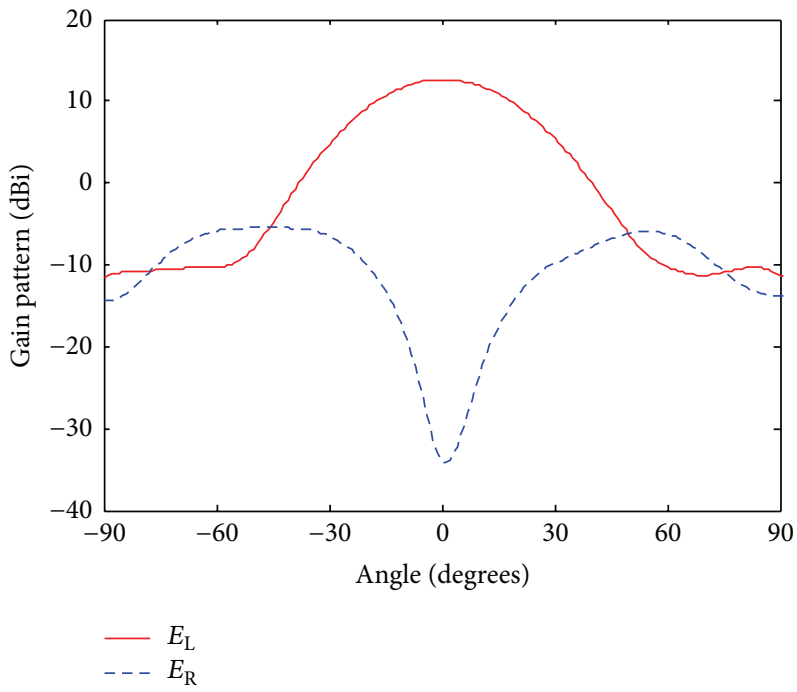

(b) $H$-plane

FIGURE 4: The $E$-plane and $H$-plane circular polarization radiation patterns of the feeding circular horn at $10 \mathrm{GHz}$.

The same behavior of the transparent conducting polymer and the PEC unit cell is achieved.

2.2. Theory of Reflectarray. Consider a $2 \mathrm{D}$ array placed in the $x-y$ plane and is illuminated by a feed horn located at $\left(x_{f}\right.$, $y_{f}, z_{f}$ ) from the array aperture as shown in Figure 3(a). The required compensation phase shift for each unit cell in the reflectarray is obtained as

$$
\begin{aligned}
& \varphi_{i j}\left(x_{i j}, y_{i j}\right) \\
& =k_{o}\left[d_{i j}-x_{i j} \sin \left(\theta_{o}\right) \cos \left(\emptyset_{o}\right)-y_{i j} \sin \left(\theta_{o}\right) \sin \left(\emptyset_{o}\right)\right],
\end{aligned}
$$

where

$$
d_{i j}=\sqrt{\left(x_{i j}-x_{f}\right)^{2}+\left(y_{i j}-y_{f}\right)^{2}+z_{f}^{2}},
$$

where $k_{o}=2 \pi / \lambda_{o}$ is the propagation constant in free space, $\left(x_{i j}, y_{i j}\right)$ are the coordinates of reflectarray unit cell, and $\left(\theta_{o}, \emptyset_{o}\right)$ is the desired direction of the main beam. Figure 3 shows the geometry of a $13 \times 13$ unit-cell reflectarray antenna covering an area of $18.98 \times 18.98 \mathrm{~cm}^{2}$ and placed on the $x-y$ plane at $10 \mathrm{GHz}$. A circularly polarized $(\mathrm{CP})$ horn antenna is used to feed the reflectarray located at a distance $F=18.98 \mathrm{~cm}$ from the array aperture. The horn has diameter $D_{\mathrm{h}}=40 \mathrm{~mm}$ and length $L_{\mathrm{h}}=40 \mathrm{~mm}$ and is fed via two orthogonal coaxial probes with $90^{\circ}$ phase shift to produce CP field. The left- and right-hand $\mathrm{CP}$ radiation patterns, components of the horn antenna at $10 \mathrm{GHz}$ in $E$-plane and $H$-plane, are shown in Figure 4 . The horn antenna introduces a maximum gain of $12 \mathrm{~dB}$ with side lobe level (SLL) of $-22 \mathrm{dBi}$ in $E$ - and $H$-planes.

A $13 \times 13 \mathrm{CP}$ microstrip reflectarray antenna is designed using the PEC patch and compared to that designed using the TCFs. The radiation characteristics of both reflectarrays are calculated using a full-wave simulator CST-Microwave Studio based on the FIT. The solution technique takes into consideration the effect of the mutual coupling between the array elements. The radiation pattern for the PEC microstrip 


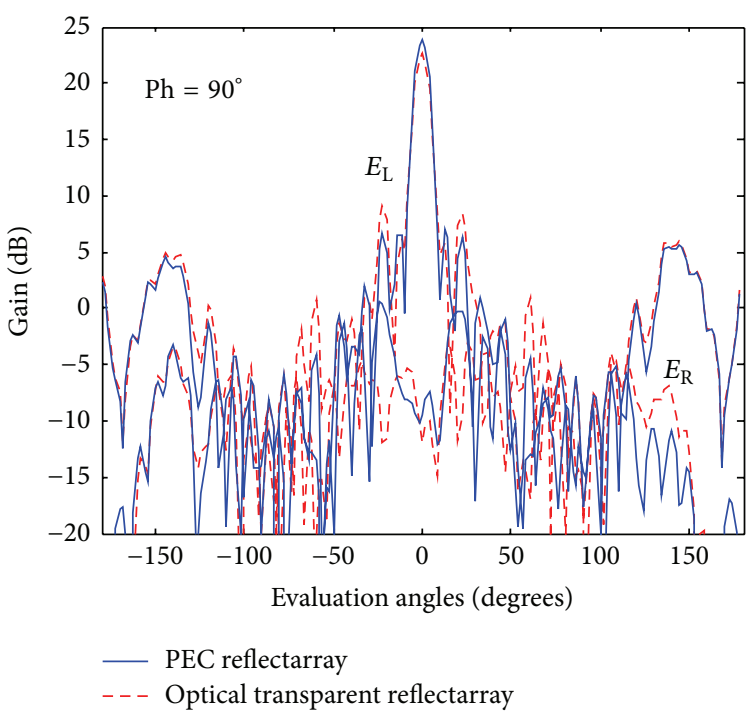

(a) E-plane

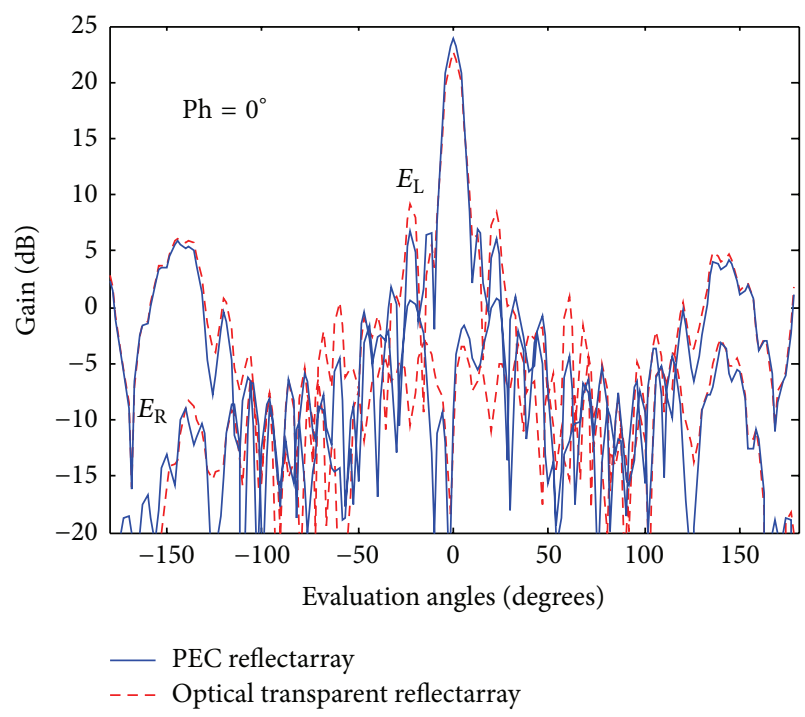

(b) H-plane

FIGURE 5: The $E$-plane and $H$-plane circular polarization radiation patterns of the $13 \times 13$ circularly polarized PEC/optical transparent reflectarray at $10 \mathrm{GHz}$.

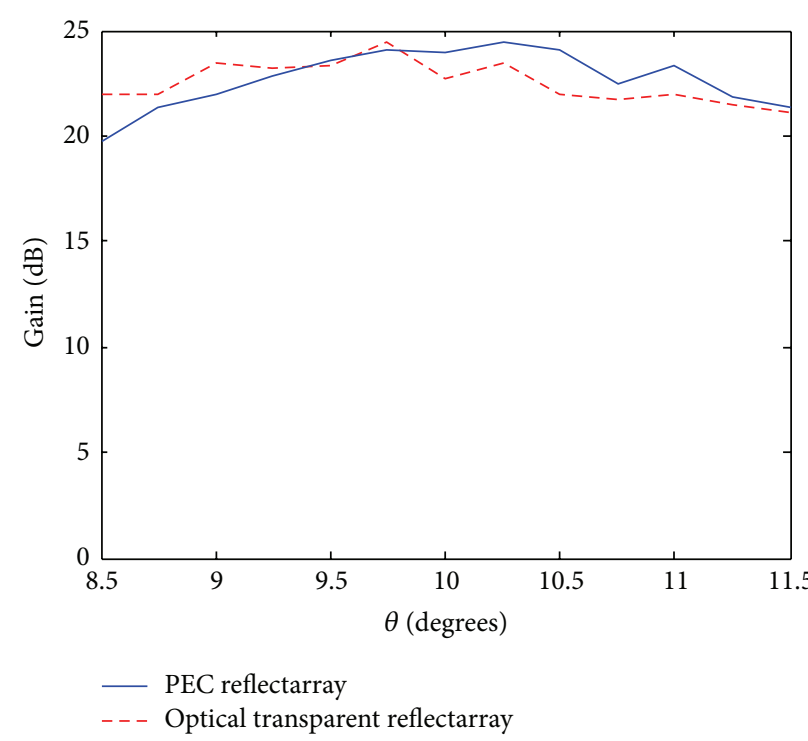

(a) Gain

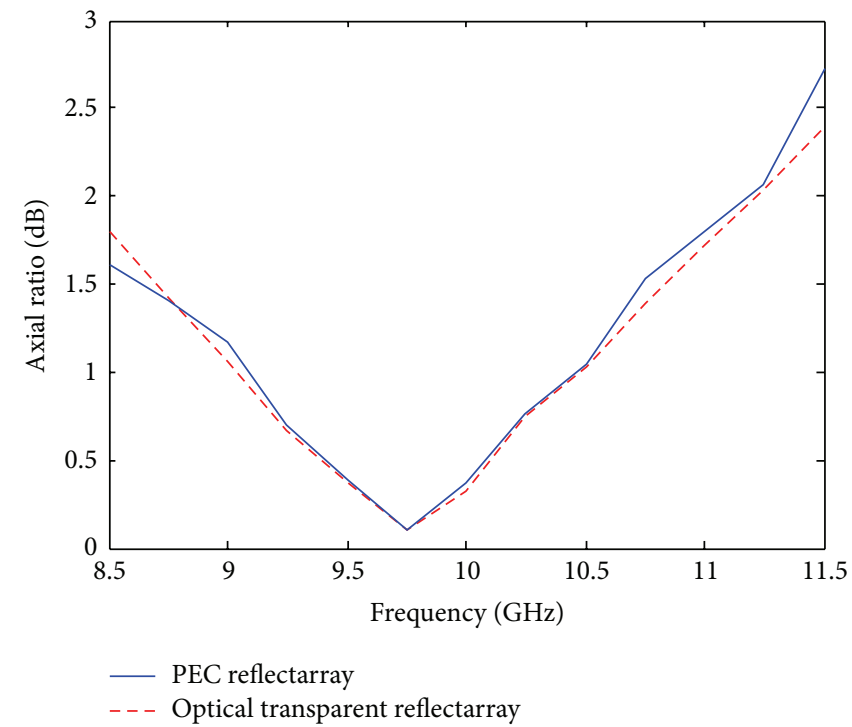

(b) Axial ratio

FIGURE 6: The gain and axial ratio variation versus frequency of the $13 \times 13$ circularly polarized PEC/optical transparent reflectarray at $10 \mathrm{GHz}$.

reflectarray and the TCFs microstrip reflectarray in different planes at $10 \mathrm{GHz}$ is shown in Figure 5. The PEC patch reflectarray has first side lobe levels (SLL) of approximately$16.3 \mathrm{dBi}$ in both the $E$-plane and $H$-plane below the main beam. The TFCs reflectarray has SLL of $-13.5 \mathrm{dBi}$ in both the $H$ - and $E$-planes with nearly the same half-power beam width (HPBW) of 5 degrees.

The gain variations against the frequency for the PEC/TFCs microstrip reflectarrays are shown in Figure 6(a). The PEC microstrip reflectarrays introduce peak gain of $24.43 \mathrm{~dB}$ with a $1 \mathrm{~dB}$ gain bandwidth of $1.15 \mathrm{GHz}(11.22 \%)$. The TCFs microstrip reflectarray introduces a peak gain of
$24.44 \mathrm{~dB}$ with $1 \mathrm{~dB}$ gain bandwidth of $0.39 \mathrm{GHz}(4 \%)$. A reduction in the TCFs reflectarray gain bandwidth is due to the reduced conductivity of the TCFs polymer compared to the PEC. The axial ratio variations versus frequency of the PEC/TFCs microstrip reflectarray is shown in Figure 6(b). Both reflectarrays produce $\mathrm{CP}$ radiation patterns with $\mathrm{AR}<$ $3 \mathrm{~dB}$ and cover a frequency range of $3 \mathrm{GHz}$ compared to that for the horn antenna.

2.3. Solar-Cells Integration with the Microstrip Reflectarray. Solar-cells integration with the microstrip reflectarray occupies the same area. The effect of solar cell position relative 


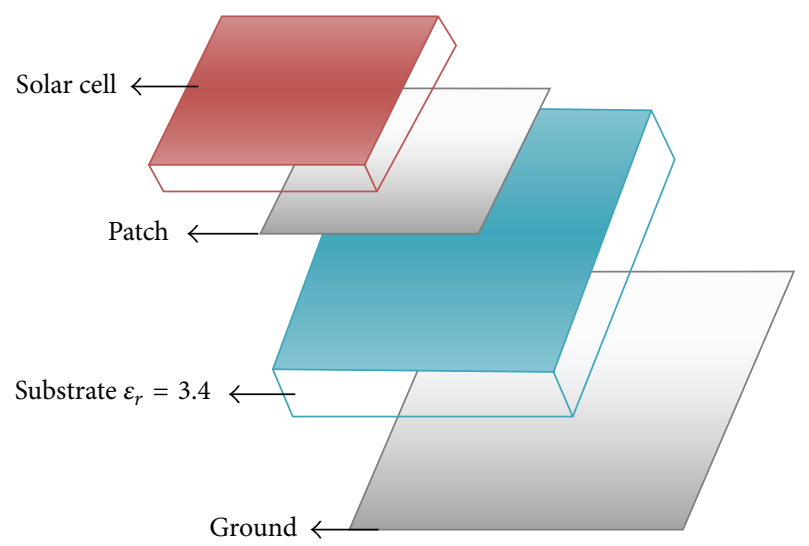

(a) The unit cell with solar cell

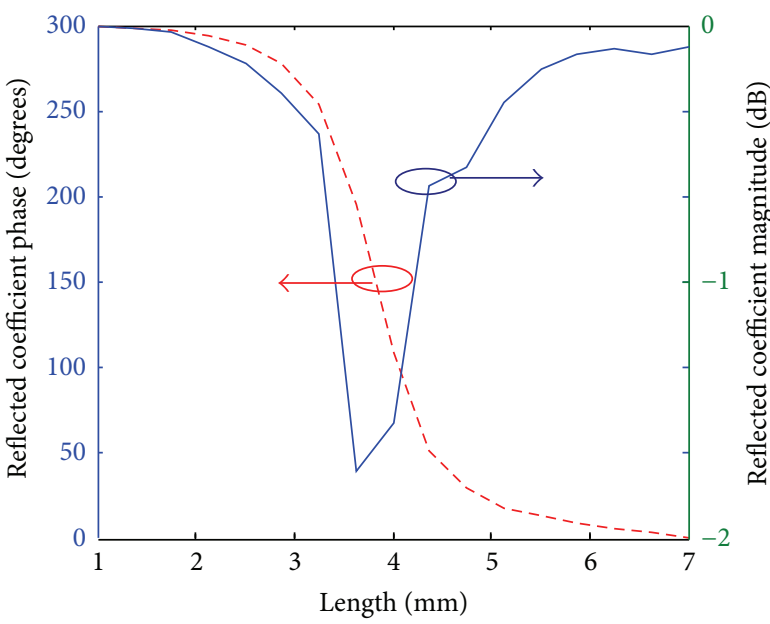

(b) The reflection coefficient variation

Figure 7: (a) The detailed construction of the optically transparent unit cell integrated with solar cell. (b) Reflection coefficient magnitude and phase variation versus the patch arm length at $10 \mathrm{GHz}$.

to the radiation element on the radiation characteristics of the transmit array is studied in [27]. The unit cell consisting of TCFs square patches printed on a dielectric substrate as described in Section 2.1 is integrated with a solar cell placed on the top of the TCFs patch as shown in Figure 7(a). The solar cell has a square shape with arm length, $a$, thickness $h_{s}=0.057 \mathrm{~mm}$, and dielectric properties of $\varepsilon_{r}=1.5$ and $\tan \delta=10$. Again the variation in the arm length of both the patch and the solar cell is used to adjust the needed reflection coefficient compensation phase of each element. The reflection coefficient magnitude and phase variation versus patch arm's length of the unit cell is shown in Figure 7(b). The minimum value of the reflection magnitude experienced by the structure is $-1.8 \mathrm{~dB}$, while the reflection coefficient phase covers approximately 300 degrees. The solar cell has an effect on increasing the magnitude of the reflection coefficient while keeping the same reflection coefficient phase variation due to the losses introduced in the solar-cell layer. Figure 8 shows the configuration of $13 \times 13$ TCFs microstrip reflectarray integrated with the solar cell covering an area of $18.98 \times 18.98 \mathrm{~cm}^{2}$. The $E$ - and $H$-plane, left-hand and right-hand $\mathrm{CP}$ radiation patterns for the TCFs microstrip reflectarray integrated with the solar cell at $10 \mathrm{GHz}$, are shown in Figure 9. The copolar/cross-polar ratio is lower than $-30 \mathrm{dBi}$ with SLL of $-13.5 \mathrm{dBi} /-14.5 \mathrm{dBi}$ in the $E$ - $/ H$-planes. The gain and axial ratio variations versus frequency is shown in Figure 10. A maximum gain of $24 \mathrm{dBi}$ is achieved. The 1 $\mathrm{dB}$ gain bandwidth variation is $1.5 \mathrm{GHz}$ with a reduction in the maximum gain by about $0.5 \mathrm{~dB}$ due to the increase in the magnitude of the reflection coefficient. The array introduces circular polarization with $\mathrm{AR}<3 \mathrm{~dB}$ and covers $3 \mathrm{GHz}$.

\section{Conclusion}

The paper introduces the radiation characteristics of a microstrip patch reflectarray antenna for small satellite applications at $10 \mathrm{GHz}$. The reflectarray antennas are used for

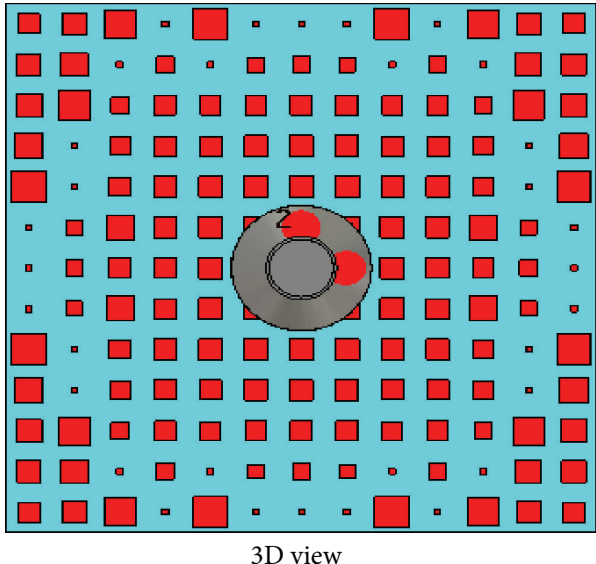

FIGURE 8: The detailed construction of the optically transparent microstrip patch reflectarray integrated with solar cell and the 3D radiation pattern at $10 \mathrm{GHz}$.

data communication and the solar cells are used for energy harvesting, saving the available surface area of emerging applications. A unit cell consists of PEC patch printed on an optically transparent substrate with the PEC ground plane. A comparison between the PEC patch and the TCFs polymer unit cell has been introduced. The same behavior of the transparent conducting polymer and the PEC unit cell is reached. The magnitude of the reflection coefficient achieves $0 \mathrm{~dB}$ nearly with $300^{\circ}$ reflection coefficient phase using patch arm's length. A $13 \times 13 \mathrm{CP}$ microstrip reflectarray antenna is designed using the PEC patch and compared to that designed using the TCFs. A circularly polarized horn antenna is utilized to feed the reflectarray. The peak gain is $24.43 \mathrm{~dB}$ with a $1 \mathrm{~dB}$ gain bandwidth of $1.15 \mathrm{GHz}(11.22 \%)$ for the PEC patch reflectarray and $24.44 \mathrm{dBi}$ with a $1 \mathrm{~dB}$ gain bandwidth of $0.39 \mathrm{GHz}$ (4\%) for the TCFs reflectarray. The solar cell is integrated with the TCFs reflectarray for area reduction. 


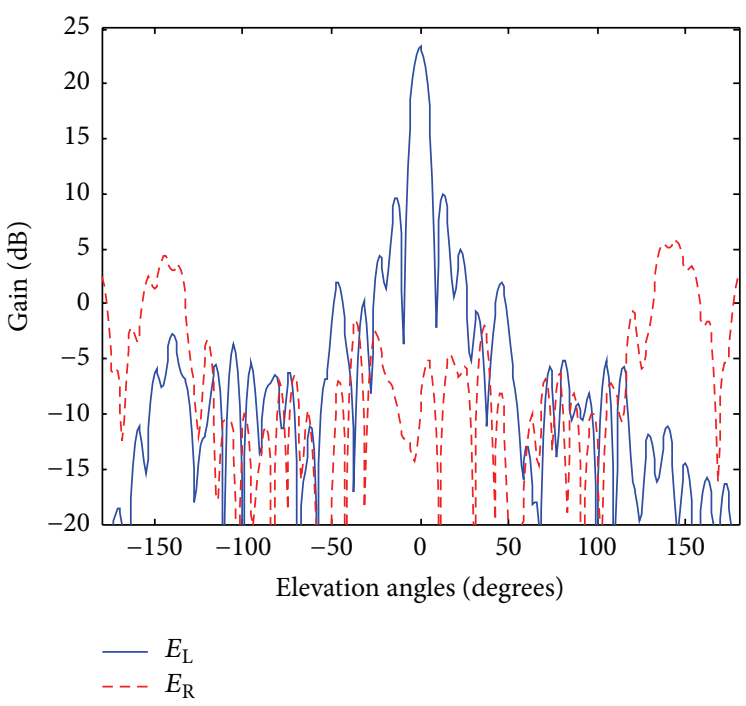

(a) E-plane

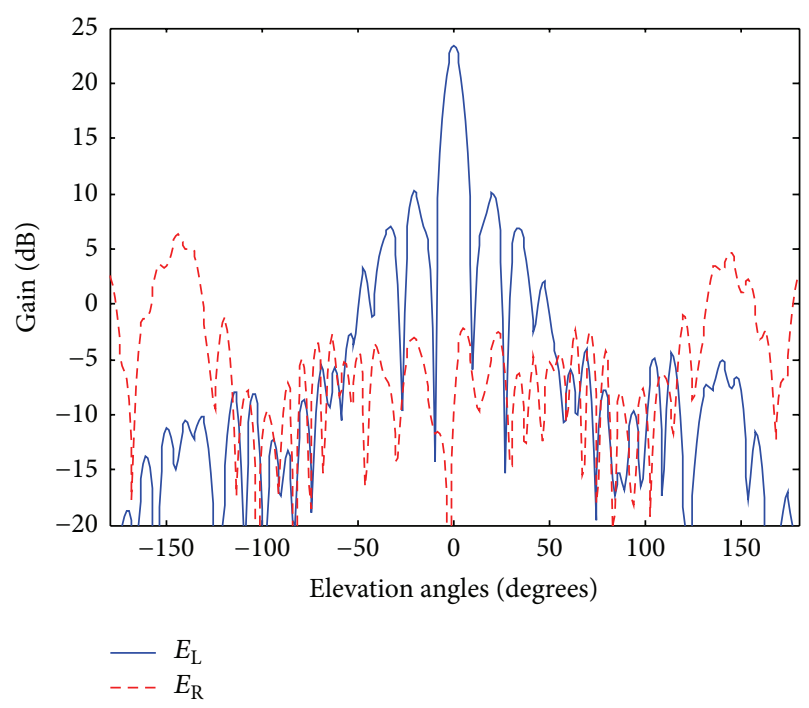

(b) $H$-plane

Figure 9: The $E$-plane and $H$-plane circular polarization radiation patterns of the $13 \times 13$ circularly polarized optical transparent reflectarray integrated with solar cell at $10 \mathrm{GHz}$.

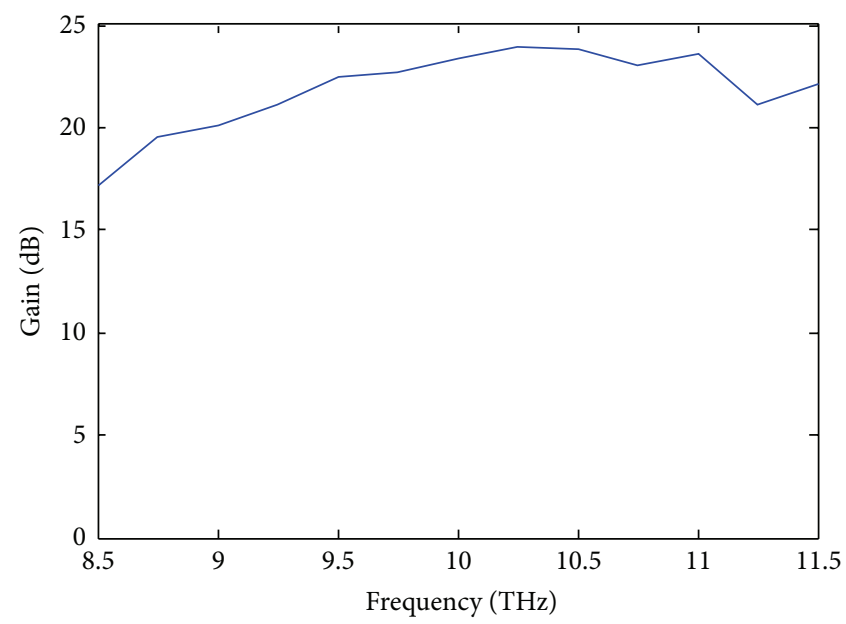

(a) Gain

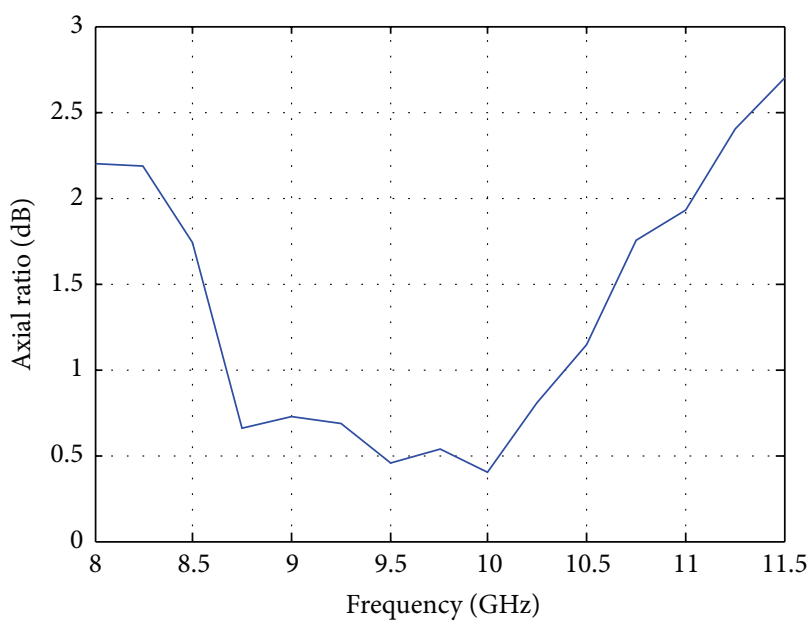

(b) Axial ratio

FIGURE 10: The gain and axial ratio variation versus frequency of the $13 \times 13$ circularly polarized optical transparent reflectarray integrated with solar cell at $10 \mathrm{GHz}$.

The solar-cell integration with the reflectarray reduces the maximum gain by about $0.5 \mathrm{~dB}$ due to the increase in the magnitude of the reflection coefficient.

\section{Competing Interests}

The authors declare that there is no conflict of interests regarding the publication of this article.

\section{References}

[1] D. M. Pozar and T. A. Metzler, "Analysis of a reflectarray antenna using microstrip patches of variable size," Electronics Letters, vol. 29, no. 8, pp. 657-658, 1993.
[2] T. Kawashima, H. Matsui, and N. Tanabe, "New transparent conductive films: FTO coated ITO," Thin Solid Films, vol. 445, no. 2, pp. 241-244, 2003.

[3] D.-C. Chang and M.-C. Huang, "Multiple-polarization microstrip reflectarray antenna with high efficiency and low cross-polarization," IEEE Transactions on Antennas and Propagation, vol. 43, no. 8, pp. 829-834, 1995.

[4] M. R. Chaharmir, J. Shaker, M. Cuhaci, and A. Ittipiboon, "A broadband reflectarray antenna with double square rings as the cell elements," in Proceedings of the 1st European Conference on Antennas and Propagation (EuCAP '06), IEEE, Nice, France, November 2006.

[5] J. A. Encinar, "Design of two-layer printed reflectarrays using patches of variable size," IEEE Transactions on Antennas and Propagation, vol. 49, no. 10, pp. 1403-1410, 2001. 
[6] J. A. Encinar and J. A. Zornoza, "Broadband design of threelayer printed reflectarrays," IEEE Transactions on Antennas and Propagation, vol. 51, no. 7, pp. 1662-1664, 2003.

[7] E. Carrasco, M. Barba, and J. A. Encinar, "Aperture-coupled reflectarray element with wide range of phase delay," Electronics Letters, vol. 42, no. 12, pp. 667-668, 2006.

[8] T. W. Turpin and R. Baktur, "Meshed patch antennas integrated on solar cells," IEEE Antennas and Wireless Propagation Letters, vol. 8, pp. 693-696, 2009.

[9] S. Sakita, H. Deguchi, and M. Tsuji, "Single layer microstrip reflectarray based on dual-resonance behavior," in Proceedings of the Intelligent Systems Applications to Power Systems (ISAP '07), pp. 1290-1293, Niigata, Japan, 2007.

[10] S. Vaccaro and P. de Maagt, "Insight experiment for combined planar antennas and solar cells (SOLANT)," IET Microwave Antennas Propagation, vol. 3, no. 8, pp. 1279-1287, 2009.

[11] S. Vaccaro, P. Torres, J. R. Mosig et al., "Stainless steel slot antenna with integrated solar cells," Electronics Letters, vol. 36, no. 25, pp. 2059-2060, 2000.

[12] K. Ito and M. Wu, "See-through microstrip antennas constructed on a transparent substrate," in Proceedings of the 7th International Conference on (IEE) Antennas and Propagation (ICAP '91), vol. 1, pp. 133-136, New York, NY, USA, April 1991.

[13] M.-S. Wu and K. Ito, "Basic study on see-through microstrip antennas constructed on a window glass," in Proceedings of the IEEE Antennas and Propagation Society International Symposium (AP-S '92) Digest Held in Conjuction with URSI Radio Science Meeting and Nuclear EMP Meeting, vol. 1, pp. 499-502, June 1992.

[14] H. J. Song, "Challenges in glass integrated optically transparent antennas," in Proceedings of the International Symposium on Antennas and Propagation (ISAP '11), Jeju, South Korea, 2011.

[15] T. W. Turpin and R. Baktur, "Meshed patch antennas integrated on solar cells," IEEE Antennas and Wireless Propagation Letters, vol. 8, pp. 693-696, 2009.

[16] T. Kawashima, H. Matsui, and N. Tanabe, "New transparent conductive films: FTO coated ITO," Thin Solid Films, vol. 445, no. 2, pp. 241-244, 2003.

[17] X. Jiang, J. Polastre, and D. Culler, "Perpetual environmentally powered sensor networks," in Proceedings of the 4th International Symposium on Information Processing in Sensor Networks (IPSN '05), pp. 463-468, IEEE, Los Angeles, Calif, USA, April 2005.

[18] J. D. Hagerty, "Radio telemetry buoy for long-range communication," US Patent 5452262, 1995.

[19] R. Morais, J. B. Cunha, M. Cordeiro, C. Serodio, P. Salgado, and C. Couto, "Solar data acquisition wireless network for agricultural applications," in Proceedings of the 19th Convention of Electrical and Electronics Engineers in Israel, pp. 527-530, Jerusalem, Israel, November 1996.

[20] D. R. Green, J. Ward, and N. Wyper, "Solar-powered wireless crosswalk warning system," US Patent 7317405, June 2005.

[21] D. A. Baker, “Telemetry power system," US Patent 7199488, 2007.

[22] G. E. Tompson, "Wireless, solar-powered, pavement temperature sensor," US Patent 7275864, 2007.

[23] K. Isoyama, T. Ohkuma, and D. Kawasaki, "Power saving wireless telemetering system," US Patent 7301477, 2007.

[24] S. Baglio, S. Gagliano, D. Neri, N. Savalli, and G. Tina, "Optimal design of photovoltaic systems for wireless sensor networks," in Proceedings of the IEEE International Symposium on Industrial
Electronics (ISIE '08), pp. 2108-2113, IEEE, Cambridge, UK, November 2008

[25] S. Vaccaro and L. Gerlach, "Combination of antennas and solar cells for satellite applications," Microwave and Optical Technology Letters, vol. 29, pp. 243-248, 2001.

[26] R. Marklein, "The finite integration technique as a general tool to compute acoustic, electromagnetic, elastodynamic, and coupled wave fields," in Review of Radio Science: 1999-2002 URSI, Chapter: The Finite Integration Technique as a General Tool to Compute Acoustic, Electromagnetic, Elastodynamic, and Coupled Wave Fields, W. R. Stone, Ed., pp. 201-244, IEEE Press, Piscataway, NJ, USA, 2002.

[27] N. A. Al-Shalaby and S. M. Gaber, "Parametric study on effect of solar-cell position on the performance of transparent DRA transmitarray," AEU-International Journal of Electronics and Communications, vol. 70, pp. 436-441, 2016. 


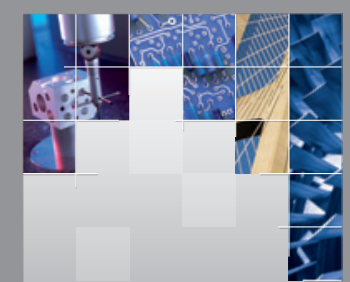

\section{Enfincering}
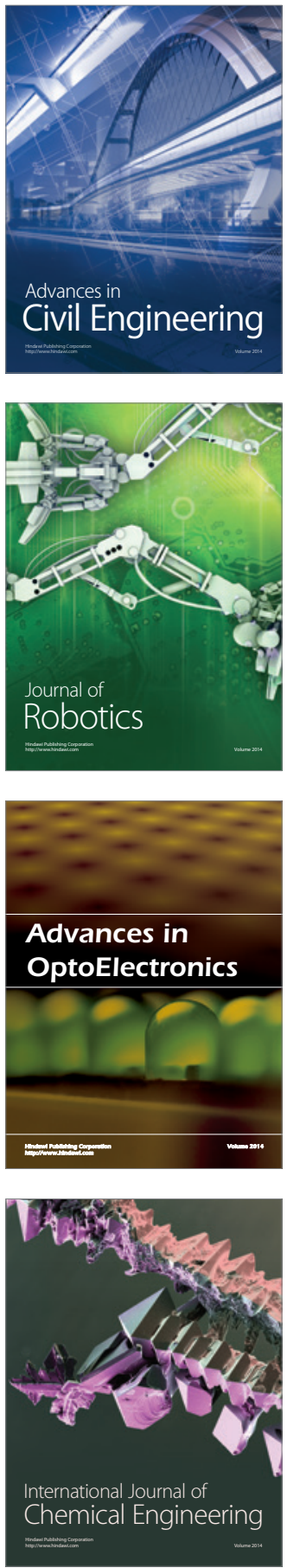

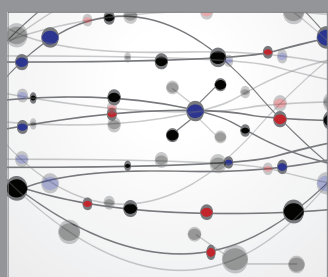

The Scientific World Journal

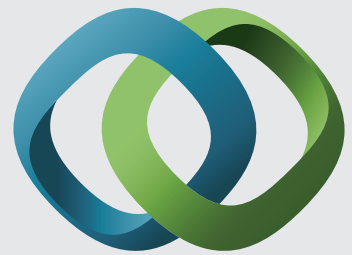

\section{Hindawi}

Submit your manuscripts at

http://www.hindawi.com
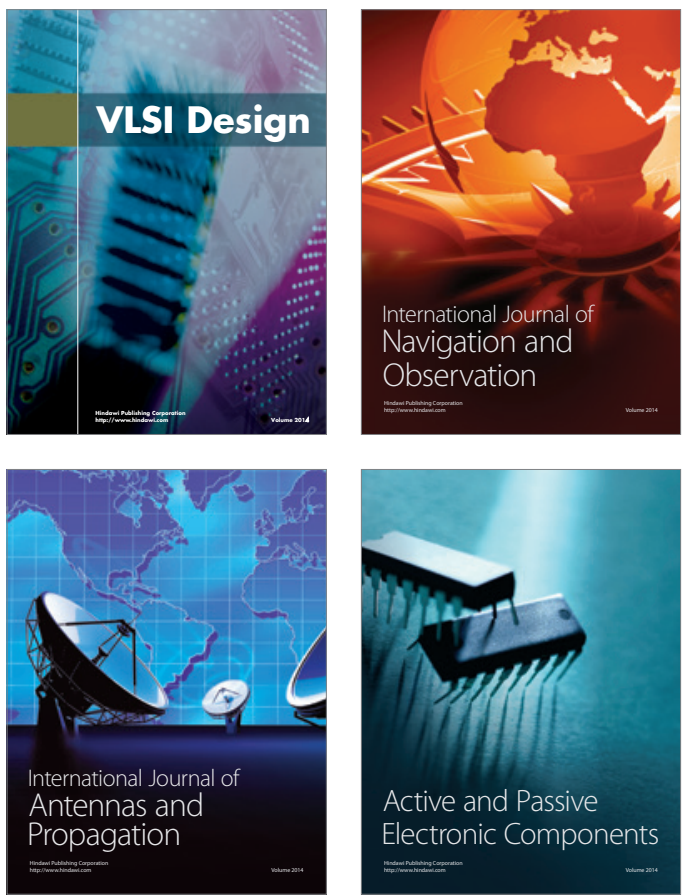
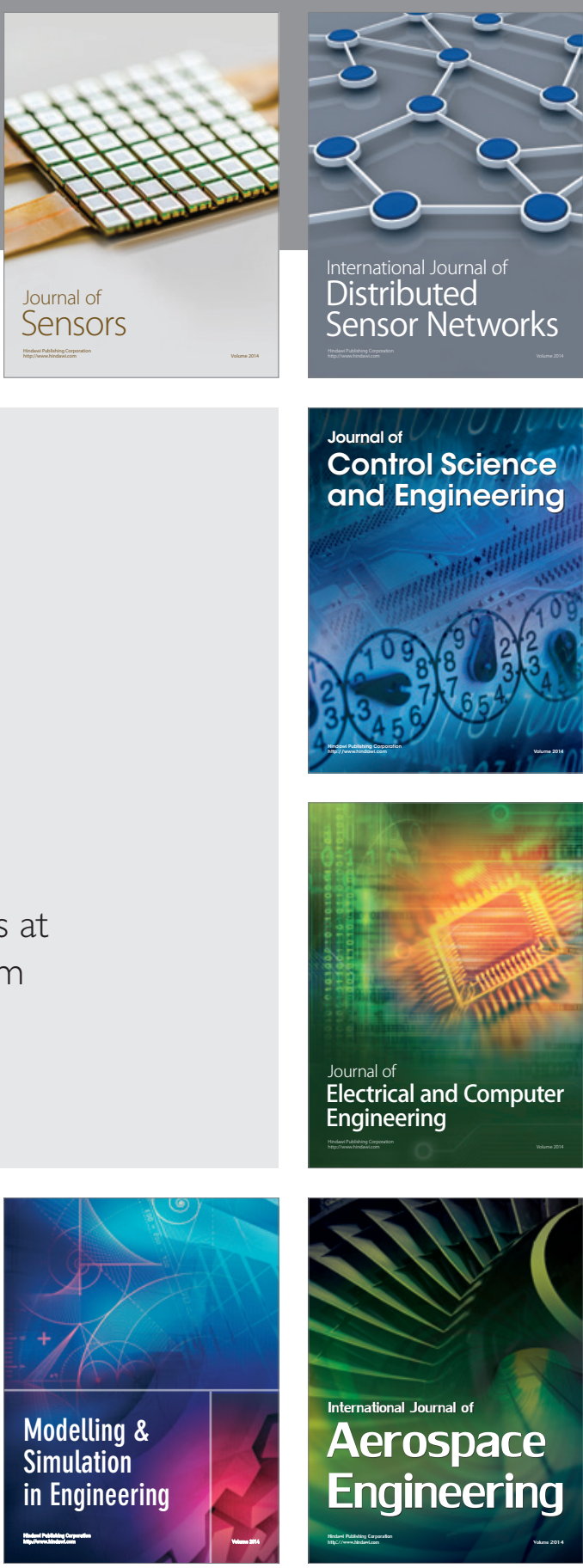

International Journal of

Distributed

Sensor Networks

Journal of

Control Science

and Engineering
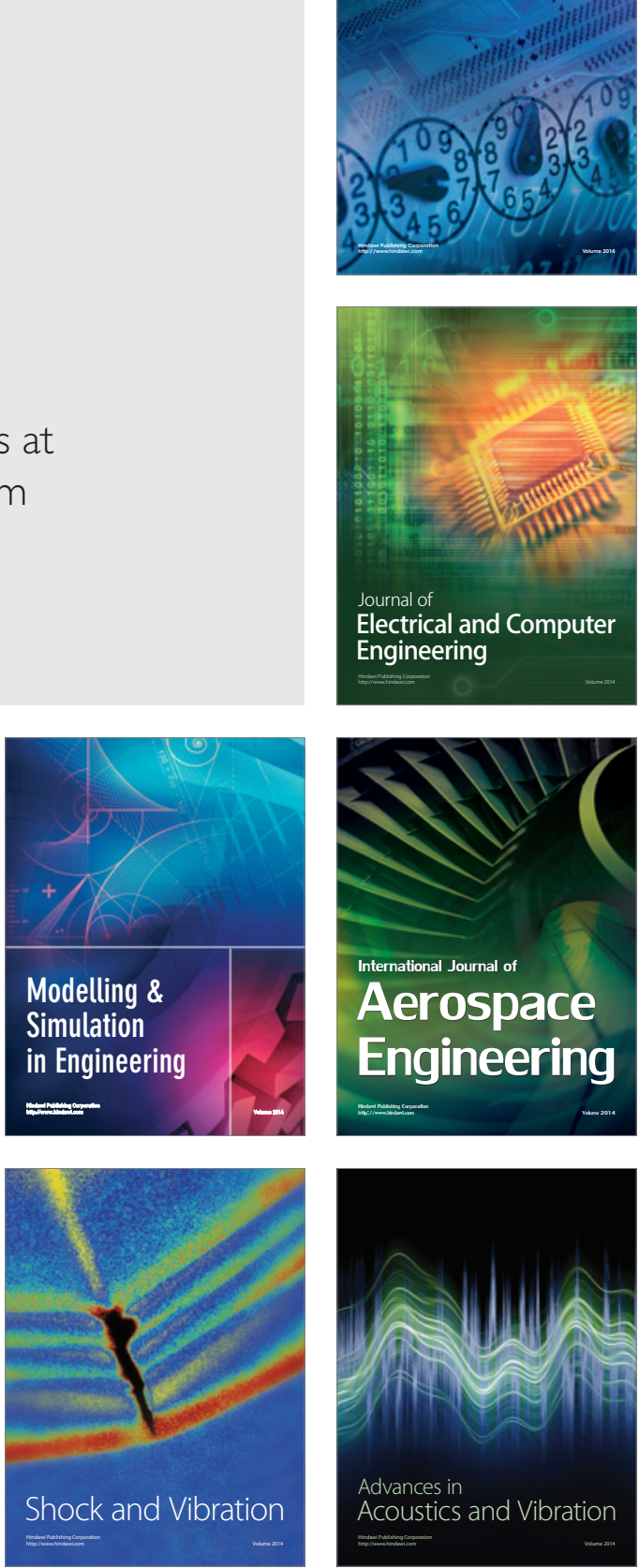